\title{
CONSTRUCCIÓN HISTÓRICA DEL PENSAMIENTO MODERNO
}

Blanca Rosa Cerpa Bustamante

\section{RESUMEN}

El permanente trabajo de búsqueda y de creación en el ser humano es origen de la cultura y del pensamiento, en tanto éste es una facultad que acompaña toda acción. Desde la antigüedad más remota, las creencias y conocimientos representaron un conjunto de preocupaciones reiterativas, que han atravesado la historia y lo han acompañado hasta hoy. Aquí se tratan algunas de ellas y su significado en el desarrollo humano. Así por ejemplo, el afán de comprender, de conocer, lo hizo un notable observador y dio lugar a la aparición de la agricultura, la que, a su vez, permitió un salto cualitativo en el estilo de vida del hombre, en la superación de algunos de sus miedos y en el desarrollo de esa conciencia primigenia sobre sí mismo y sobre el medio. El mito es también una de las creaciones representativas de ese afán indeclinable de fijar el pensamiento, las creencias y los hechos. La historia y otros relatos son derivaciones especializadas. Los componentes ideológicos modernos tienen en general un origen lejano: la razón, la importancia del análisis y la crítica, la vocación por el registro, la idea de progreso, etc.

Palabras claves: razón, crítica, progreso, historia, conciencia

\begin{abstract}
The permanent work of searching and creation in the human being is the origin of culture and thought, as it is a capacity that accompanies every action. Since ancient times, beliefs and knowledge represented a repetitive set of concerns, which have passed through history and have been with him until today. Here we spoke about some of them and their significance in human development. For example, the desire to understand, to know, made to the human a remarkable observer and this resulted in the emergence of agriculture, which in turn enabled a meaningful leap in the lifestyle of man in overcoming some of his fears and in the development of this primal consciousness about himself and on the environment. The myth is also one of the representative creations of that unwavering desire to hold his thinking, beliefs and facts. The story and other tales are specialized referrals of that desire as well. The modern ideological components generally have a distant origin: reason, the value of analysis and critique, history o vocation for recording, the idea of progress, etc.
\end{abstract}

Key words: reason, review, criticism, conscience, awareness, history, progress. 


\section{INTRODUCCIÓN}

Al revisar las distintas clases de respuestas que surgieron desde la Antigüedad ante las inquietudes humanas, al constatar la emergencia de acontecimientos más o menos esperados, más o menos fortuitos y que conducían, ya sea a una situación más promisoria o a una que amenazaba acarrear desgracias en cadena, es que se formulan y desarrollan una serie de conceptos cuyo éxito desigual pasará a constituir la materia prima del pensamiento social, ya sea teórico, doctrinario o como expresión comunitaria de una mentalidad. No se trató de una manera de pensar homogénea, aunque sí puedan identificarse ciertas unidades de pensamiento que obedecían a propósitos definidos para resolver determinadas inquietudes, problemas o urgencias exosomáticas diversas. Aquí consideramos que, además de estos imperativos ambientales, conectados con ellos pero pertenecientes a la especie humana, a su naturaleza, existen inclinaciones $\mathrm{y} / \mathrm{o}$ vocaciones que, por ser universales, han dado lugar a productos culturales de la misma clase, aunque con diferentes matices según lugar y época, entre ellos los del pensamiento.

Si aceptamos lo que afirma A. Weber ${ }^{1}$ la definición del ser humano como el ser vivo que distinguió desde sus épocas primigenias que hay un mundo "bien definido frente a él", lo que a su vez le permitió desde entonces tener conciencia de su propia existencia, podemos encontrar allí, en esta doble percepción, el origen de sus preocupaciones sobre la vida, su devenir, su futuro, etc. Este encuadre del yo más el entorno significó también, simultáneamente, erigirlos como objeto doble del conocimiento, la imaginación, los experimentos y ensayos, es decir dominio y acción.
Desde sus orígenes hasta el presente, el trajinar de los seres humanos ha tenido esa doble misión, ese anclaje que lo fija a un espacio determinado y que lo ha habilitado también para crear otros mundos paralelos, transformarlos constantemente, rechazar unas fórmulas para adoptar otras, encajarlas, armonizarlas, estudiarlas, todo lo cual es creación de cultura.

No es, por lo tanto, que hayan existido tres tipos de hombre, como sostenía Weber, sino múltiples configuraciones culturales con resultados tan distintos que confirman la infinita capacidad humana para crear numerosas alternativas a partir de unas condiciones naturales e histórico-sociales. El conjunto de rasgos que sirven para caracterizar al supuesto primer tipo de ser humano: el Hombre de Neanderthal, portador de la cultura musteriense, fue su legado a nuestra especie: el culto a los muertos, la creencia en la inmortalidad, la recolección y la caza como actividades fundamentales de sobrevivencia, la manufactura de instrumentos de piedra, los conocimientos prístinos del medio natural a partir de una observación acuciosa, etc. Ese ser antiquísimo que se extinguió hace unos 30000 años $^{2}$ ya tenía en sí el ansia de perseverar y no solo de sobrevivir. El culto a los muertos sigue vigente hoy en día al igual que la creencia o convicción de inmortalidad ${ }^{3}$. Solo nuestros ídolos modernos ${ }^{4}$ pueden llevarnos a afirmar que el hombre de Neanderthal fue un hombre de "personalidad débil", basándonos solo en la escasa prominencia del mentón e ignorando todas las habilidades, fuerza e inteligencia que tuvo que movilizar para sobrevivir. No se le puede culpar de haber desaparecido ni atribuir con ligereza a su pretendida debilidad esa desaparición cuando sabemos que el universo todo (y todo 
lo que está en él) tiene unos límites de existencia.

El llamado segundo tipo de hombre es en realidad una etapa caracterizada por nuevas capacidades derivadas del para entonces ya extenso desenvolvimiento de nuestra especie y de las experiencias acumuladas en cientos de miles de años. Pero en la condición fundamental del espíritu humano permanecieron sus raíces originales: los conceptos de lo sagrado enlazado al culto de los muertos y al deseo de inmortalidad, así como las experiencias afirmadas de sus primeras actividades económicas en continuo perfeccionamiento. Aparecen nuevas industrias y se perfeccionan las antiguas a la par que surgen otras formas de ver el mundo y de dominarlo. El "peculiar sentido de transcendencia" y el "afán de profundidad" no son signos de una nueva especie o "tipo de hombre", aunque algunos rasgos morfológicos cambien; es el ser humano que está complejizando su vida, que ha aprendido a elaborar nuevos artefactos y a mejorar los antiguos, a la vez que sus dotes creativas se han potenciado según el medio natural en que se ha desenvuelto, según los resultados transaccionales con sus semejantes $\mathrm{y}$, por consiguiente, según las tradiciones que portaba. Se trató de un explorador indesmayable por la crudeza del mundo que le tocó vivir, pero allí mismo entró en juego todo su potencial: necesidad, proyectos y sueños se amalgamaron. No es otra clase de ser humano el que quiere conocer, inventa y experimenta.

El tercer tipo de hombre al que nos remite Weber es el horticultor que rápidamente se va a convertir en agricultor incipiente, desde hace unos 10000 años cuando se produce la Revolución Neolítica. En el Perú es la época que corresponde al Arcaico.

\section{EL SIGNIFICADO DE LA AGRICULTURA}

En el afán migratorio en busca de nuevos espacios y posibilidades, que corresponde en Weber al segundo tipo de hombre, las fuerzas requeridas no provienen solo de los apremios vitales sino también de las expectativas; solo se avanza un tramo en la vida para conseguir algo que muchas veces está al cabo. Así pues no es descabellado pensar que esos lejanos seres del Paleolítico ya llevaban en sí la simiente de buscar algo mejor, que no es otra que la idea elemental de avance, mejora o progreso. Sin un desarrollo excepcional de sus capacidades de observación y experimentación, sin fuerza de voluntad y comprensión del poder superior que da la unidad y la cooperación esas gentes no habrían inventado la agricultura ni accedido a la multitud de beneficios que ella trajo consigo. Los "plantadores" más lejanos, es decir los del tercer tipo de hombre como los llama Weber, aparecen unos 10000 años atrás y no en un solo lugar, como sugiere dicho autor. La agricultura aparece independientemente en el lejano y cercano oriente, en América y en África. Al parecer a Europa llega después, por difusión desde Oriente Próximo o desde África, lo cual no fue tomado en cuenta por Weber.

Las condiciones climáticas planetarias favorecieron esa relativa simultaneidad; sin embargo, su importancia para la humanidad fue tan grande que a partir de entonces todo fue distinto para ella: sedentarismo, asentamientos permanentes con sus correspondientes organizaciones territoriales, económicas y sociales; construcciones; vida normada; orden político y el consecuente crecimiento notable de la población. Y, además de todo 
lo que ya se conoce exhaustivamente sobre el salto cualitativo que produjo la revolución neolítica, hay dos puntos conexos especialmente significativos para el presente estudio: Primero, la agricultura fue para entonces el gran éxito en el antiquísimo esfuerzo del Hombre por dominar la naturaleza; fue el premio mayor después de cientos de miles de años actuando sobre un medio entre hostil y generoso. Segundo, ese control era verificable en el corto plazo; se podían hacer previsiones, ordenar mejor en el tiempo actividades de distinta índole y esperar resultados seguros sin tener que afrontar, en principio, grandes riesgos. Aunque la caza también supuso una programación, fue imprevisible en diferentes sentidos, además de entrañar más peligros y de demandar un esfuerzo masivo. Se puede por eso atribuir a la agricultura la simultánea y original conciencia del valor superior de lo comunitario al lado de lo particular e individual.

Con la agricultura se afirma la confianza de la gente en sí misma en base a su trabajo. La percepción del territorio como objeto de trabajo, de organización, de control del tiempo, no sólo abre un mundo nuevo a los conocimientos y al desarrollo intelectual sino que la secuencia temporal, de hecho conocida desde mucho antes e introducida eficientemente en la configuración sociocultural, adquiere una nueva significación. Al controlar sus medios de sobrevivencia los seres humanos se hacen conscientes también del control que de hecho pueden ejercer sobre el tiempo y el espacio. Y aquí reside, si no el origen, la consolidación de sus ideas sobre proceso histórico, sobre las posibilidades de alcanzar expectativas concretas; es decir, lograr acceder a una situación superior (cosecha) a la previa (arado y siembra), raíz intelectual, volitiva y pragmática hacia algo que se sabe de antemano mejor y deseable, que no abandonará más a la humanidad, aunque con matices distintos en occidente, oriente y América.

Sin la agricultura no habrían surgido ciudades ni estados ni grandes complejos hidráulicos ni comercio ni otras fructíferas formas de interrelación. Las manufacturas y otras formas de transformación, aunque son muy anteriores a la agricultura, no se habrían diversificado como lo muestra la historia de los miles de pueblos en los cinco continentes. La cultura es pues una compleja y permanente creación social humana e incluye, como ya ha sido ampliamente trabajado por antropólogos, sociólogos y humanistas en general, conocimientos, creencias, religiones, doctrinas, ciencia, mitos y toda otra producción intelectual, tanto como ordenamientos, instituciones, construcciones, tecnología, etc.

\section{REPRESENTACIÓN DE LA REALIDAD Y LA CONCIENCIA}

La humanidad desde sus orígenes más remotos ha intentado resolver cuestiones ineludibles que han marcado su recorrido. La observación de su medio, la necesidad imperiosa de ordenarlo todo; sus relaciones interpersonales; el enfrentamiento con problemas vinculados a su sobrevivencia; la presencia de otros grupos con similares situaciones pero con respuestas y resultados distintos; la eminencia del peligro que convierte al espectáculo de la naturaleza en una amenaza y a la interacción humana sociocultural, política e incluso interpersonal en riesgo permanente de conflicto, en peligro para la sobrevivencia, son todos ellos factores que inciden en la ideología, la cosmovisión, el pensamiento especulativo y toda otra forma de represen- 
tación de la realidad. La conciencia es el reconocimiento de esa realidad, su identificación y actualización constante a través de la experiencia, de allí que Whitehead vea en la conciencia la manifestación de esta última. De hecho, se asume la coexistencia de lo real con la experiencia ${ }^{7}$.

Los campos de interés fundamentales a la vida del hombre tienen como motivación de origen el comprender y el resolver, pero los productos resolutivos, deberán ser satisfactorios y convenientes en el sentido de ser útiles a la sociedad, a la vez que agradar y atender a los deseos profundos de las personas o lo que ellas más aprecian. Los seres humanos crean cultura dentro de la cual está el pensamiento y las ideas para resolver constantemente problemas, apelando a diversas fórmulas; todos los productos que componen la cultura existen para atender demandas de respuestas concretas en torno a alguna preocupación específica o a un conjunto asociado de problemas. Si aceptamos que hay una ley universal que propende a realizar economías en todo y, antes de ella, que todo hecho humano es antecedido por un propósito, causa o, al menos, un impulso que le da origen, se puede convenir que nada perteneciente a la creación humana es antojadizo o inútil, más allá de apreciaciones interesadas, etnocéntricas o contingentes, basadas en valores y consideraciones inmediatas.

De aquí resulta que la religión, la magia y el mito, como el lenguaje, la agricultura, la construcción, la textilería, etc. son producciones con sentido que, además, una vez creadas, no son abandonadas, lo que prueba su eficiencia. En cuanto a la conciencia, pertenece al campo de la interioridad, pero a la vez se le asume como principio divino, razón por la cual acompaña a la humanidad desde sus orígenes, no así la reflexión sobre ella. "El uso filosófico de la noción de conciencia presupone el reconocimiento de la realidad de esta esfera y el de su naturaleza privilegiada" ${ }^{\prime 8}$.

En Habermas, la conciencia equivale a la parte de la cultura que se deposita en la mente de los miembros de la sociedad-cultura, bajo la forma de convicciones, expectativas, visión del pasado presente y futuro, pero siempre con un referente: el pasado cuando se piensa y habla del presente, y éste cuando se proyecta al futuro, lo cual está en la base de la conciencia histórica ya prevista en la idea de secuencia. La conciencia así entendida incorpora la concepción de la vida, de la humanidad y de los cambios esperados, todo lo cual explica su relación con diferentes procesos de creación cultural, como los mitos, el culto a los muertos, la vocación religiosa. Es esa relación primigenia la que emparienta las necesidades que dan origen a los mitos con las de registro, por ejemplo, manteniendo sus diferencias que se sustentan en que cada producto cultural cumple un conjunto distinto de funciones.

Particularmente el mito, la religión y la magia han sobrevivido, no milenios, sino cientos de miles de años, y continúan siendo instituciones tan actuales que la sacralización de la ciencia ni otras formas de conocimiento o de búsqueda de dominio sobre fenómenos, cosas, personas u otros seres las han debilitado. Si, por ejemplo, se trata de indagar cuál es el origen del mito, hay que preguntarse por los problemas que se pretendió resolver, en qué medida sigue siendo respuesta a un interés original de relación con el entorno y cuáles otros imperativos posteriores y/o más 
recientes mantienen su vigencia. De algún modo, esta búsqueda de un origen común quizá tenga que ver con esa necesidad de comprender "lo que de invariable hay en la enorme diversidad" humana, como ha sido expuesto y ejemplificado por Lévi-Strauss".

\section{LA CONCIENCIA MÍTICO- HISTÓRICA Y LA CONCIENCIA HISTÓRICA}

La conciencia histórica según Cassirer ${ }^{10}$ aparece cuando el ser humano empezó a darse cuenta del problema del tiempo, "cuando ya no se hallaba confinado en el estrecho círculo de sus deseos y necesidades inmediatas, cuando comenzó a inquirir el origen de las cosas".

Hasta ese momento solo había podido encontrar un origen mítico y no histórico. Así Cassirer quiere marcar la diferencia entre mito e historia dentro de un esquema evolutivo; aquél pertenecería a una época de indiferenciación, de estrechez de pensamiento, mientras que ésta, la historia, representaría unas capacidades intelectuales más desarrolladas porque los seres humanos "empiezan a darse cuenta". Aquí tenemos esbozado uno de los mitos más entrañables de la modernidad: el mito del progreso, instalado plenamente con la ilustración y exitosamente difundido en todo el orbe hasta la actualidad.

Cuando Cassirer dice que la conciencia histórica es un producto verdaderamente tardío de la civilización, que no existió antes de los historiadores griegos y que recién en el siglo XVIII alcanza su madurez, más allá de lo discutible de esta hipótesis, nos está ofreciendo las pautas para comprender el nexo entre mito e historia. La pregunta que debemos res- ponder previamente es: cuál es el punto que queremos aclarar; quizá sea el origen de la narración histórica en su versión moderna, o el origen de los relatos de acontecimientos que sucedieron en la antigüedad o en la edad media; o quizá más bien lo que quisiéramos descubrir es eso que en común tienen los más antiguos relatos míticos y los registros de hechos, con los posteriores, con las más versadas y mejor reglamentadas formas de conservación de los hechos del pasado, su análisis e interpretación. Más allá de esta aclaración previa, la existencia de un hilo conector ya está sugerida en Cassirer " cuando afirma que "en el mito es donde encontramos los primeros ensayos para establecer un orden cronológico de las cosas y los acontecimientos, para ofrecer una cosmología y una genealogía de dioses y hombres".

Habría existido, en consecuencia, la intención de satisfacer una necesidad primigenia de interpretar y apropiarse del entorno. En qué consistió esa especie de imperativo y cómo cambió hasta hacerse cada vez más multifactorial y llegar a los tiempos actuales, son preguntas que pueden servir para trazar unas rutas hacia su develamiento y para encontrar algunas respuestas tentativas o transitorias. Lo que la investigación hasta hoy demuestra es que ya en las gentes del extenso período lítico y en el arcaico (horticultores y agricultores incipientes) existió una conciencia del paso del tiempo y de los cambios que en ese trayecto se producían, una conciencia que se podría nombrar como míticohistórica, pero que no es exactamente elemental, sino más bien compleja porque tuvo que satisfacer varias exigencias a la vez.

Aunque viejas palabras y antiguos conceptos, como todo producto cultural, están tam- 
bién sometidos a la acción del tiempo, la modernidad parece padecer de una tendencia general en la humanidad, en su expresión social como en la individual, de creer que todo nace con ella y una forma de obedecer a esta propensión es negando la existencia de muchas ideas, instituciones y costumbres en épocas anteriores. Quizá se deba a que el presente actualiza "automáticamente" ideas y logros del pasado como fórmula que aplica el principio de economía a la recapitulación, el registro, los recuerdos, a los que el ser humano es tan afecto. Una expresión de esa tendencia es la que se observa en la generación joven respecto a las que la precedieron.

A propósito de la aparición de la conciencia histórica, Bruno Snell ${ }^{12}$ dice que ella puede ser entendida de tres maneras: La primera, como "conciencia de la continuidad en el tiempo y de la unidad radical de los acontecimientos"; la segunda es la "conciencia de la importancia del pasado para el presente"; finalmente, la tercera, es la conciencia "de la interconexión causal de los sucesos". El punto problemático es que en los tiempos primitivos, según Snell, no pudo existir la conciencia histórica, como tampoco la historiografía correspondiente. La conciencia histórica en los tres significados que le da Snell, aparece en la historia humana muy tempranamente, aunque es difícil asegurar cuándo. Sin embargo, toda vez que esa conciencia no es idéntica a lo largo del tiempo sino que ella depende de cada época y se ajusta a las exigencias de cada una, habría que diferenciarla. El descubrimiento del tiempo debió ser antíquísimo por su importancia relacional y, de hecho, con la aparición de la agricultura, ya no fue posible relegarlo a un segundo plano.
La conciencia histórica como interconexión causal de los sucesos se fortalece con su significado económico y social. Al surgir las primeras ciudades y los pueblos organizados también hacen su aparición la conciencia histórica, el mito y otros valores culturales del pensamiento, que se constituyeron en eslabones ideológicos que sostenían y articulaban esa conciencia con los logros alcanzados y con el afán de permanecer frente a otros grupos humanos. La conciencia histórica se convirtió en el soporte social, político e ideológico por excelencia precisamente por ese rol conectado a la voluntad de salvaguardar la tradición cultural, que es uno de los recursos inventados para seguir siendo. Así pues, su asociación con el registro de los hechos y otras fórmulas recordatorias, como son los mitos, genealogías, crónicas, historia, entre varias más, revela esa antigua voluntad de perseverar. Habermas dice que la modernidad se caracteriza por una nueva conciencia histórica, cuya fuerza subversiva es la "intención anarquista de hacer estallar la continuidad de la historia ",13. Términos como Nova aetas o Edad Moderna expresan esa concepción ${ }^{14}$, que, junto con otros términos de la Ilustración, fue acuñada en el siglo XVIII. Por su parte Koselleck ha dicho de la conciencia histórica que "constituye una mirada transida de filosofía de la historia: un hacerse reflexivamente cargo de la propia posición desde el horizonte de la historia en su conjunto",

Si tomásemos la definición de conciencia histórica de Snell o de Cassirer como conciencia del tiempo, del antes, el después y la conexión causal entre hechos, no es posible admitir su aparición tardía. Al contrario, es probable que en el larguísimo período de la caza y la recolección el ser humano haya cua- 
jado y afirmado esa conciencia. Sin la constatación de que ciertos actos deben preceder a otros, esos antiguos pobladores de la tierra y sus culturas no hubieran podido sobrevivir; ni siquiera hubieran podido organizar una correría de caza, menos aún cada una de las múltiples actividades que la antecedían ni las que la continuaban: selección y recolección de piedras para fabricar armas e instrumentos, la manufactura de ellos, la observación paciente de las formas de vida de los animales, localización de abrevaderos, aprendizaje de ciertas destrezas para un resultado feliz de la caza, sajar la carne, raspar las pieles, etc. Pretender que necesitaron dos millones de años o más para tener conciencia del tiempo responde a nuestra indeclinable vocación de sentirnos el eje del universo en los tiempos actuales. Esto no significa creer que la conciencia histórica de hace 500,000, $100,000,10,000$ o de sólo 300 años atrás sea la misma, menos aún que las respuestas y productos culturales que resultaron de esos móviles y de otros factores a lo largo de la historia humana sean idénticos. Significa sólo que, entendida como la proponen Cassirer y Snell, la conciencia histórica ya tenía que haberse posesionado de las gentes desde tiempos prehistóricos.

Provisionalmente y, a modo de hipótesis, la humanidad ha pautado su comportamiento a partir de una poderosa voluntad de apropiación del mundo. Este postulado coincide en líneas generales con lo que dice LéviStrauss ${ }^{16}$ de los "hombres primitivos", "quienes son movidos por una necesidad o un deseo de comprender el mundo que los circun$d a$ ". Desde entonces hasta acá las formas que encontró para lograrlo fueron muy variadas: desde la observación acuciosa de cada objeto, planta, animal o fenómeno celeste que se le ponía delante hasta asignarles a cada cual un nombre específico; desde la recolecta hasta la agricultura; desde la caza a las crianzas; desde todas las clases posibles de copias o reproducciones hasta fórmulas ceremoniales y rituales que permitieron "atrapar" las fuerzas contenidas en los seres o fenómenosobjetivo. $\mathrm{Y}$ esto último es significativo para comprender otro de los componentes de la conciencia histórica: la proyección al futuro, tan importante en los conceptos de orden y progreso.

\section{EL RELATO COMO APROPIACIÓN DEL MUNDO}

La reiteración regular de muchas de las apropiaciones humanas, a través de la reproducción, como dibujos, ritos, danzas, oraciones, sacrificios, etc. hizo imprescindible el lenguaje: desde la emisión de sonidos onomatopéyicos, siguiendo con los nombres, los vocablos referidos a cosas que hace la gente, los animales, las plantas, los truenos, etc. La complejización de la vida y la necesidad de resolver problemas acuciantes juntamente con toda su experiencia previa lo llevó a la construcción de relatos: pintados, contados, repetidos una y otra vez en ceremonias y fiestas, durante el trabajo manufacturero, en la enseñanza a niños y jóvenes, etc.

El mito emerge para satisfacer distintas necesidades simultáneas: explicación del mundo, perennización de algunos hechos importantes, actualización de acontecimientos significativos para el pueblo o linaje, a través de recursos anamnésicos muy variados, consolidación de creencias y valores, forja de la identidad para perseverar en el tiempo. Los primeros relatos míticos probablemente estuvieron referidos a los orígenes de grupos huma- 
nos diferenciados que poblaban los lugares más conocidos y transitados, sus cosmologías y los seres poderosos escondidos en cielos, montañas, bosques, cavernas. Todos los pueblos han producido esta clase de relatos cuya intencionalidad más arcana ha sido descifrar y literalizar el mundo, el medio, la vida y todo lo que allí ocurre, es decir repetirlos. En esencia es lo mismo, con otros recursos, métodos y fines adicionales según la época, que hacen los científicos, los genetistas, los literatos, por mencionar algunos ejemplos ${ }^{17}$.

Aunque se puede suponer que la tendencia original haya buscado apropiarse de situaciones determinadas, los relatos se refirieron muy rápidamente a secuencias de hechos o fenómenos, quizá, como dice Lévi-Strauss, de "ambición totalitaria", pero estoy en desacuerdo con él de que tal cosa haya significado un fracaso en su objetivo de darle al hombre mayor poder material sobre el medio. Ciertamente, lo que se busca es lograr dominio sobre el entorno, pero no necesariamente dominio científico. Le dio poder en aquellos espacios que era urgente controlar: proveyó de explicaciones que permitieron normar y orientar el quehacer humano, acatar ciertos mandatos, manejar una cierta clase de orden, etc. No hay fracaso si cumplieron su cometido o crearon caminos para llegar a él. Los objetivos actuales no fueron los de entonces ni tenían por qué serlo.

La ciencia estudia la realidad. Para ello el científico la petrifica, la desmenuza para comprenderla en sus raíces causales y, luego, intenta reconstruirla y lo hace idealmente, organizadamente, según unos cánones previamente establecidos, principios y leyes que descubre o inventa. El mito interpreta la realidad a su manera, tomando como premi- sa su carácter móvil, su sujeción a muchas fuerzas externas; como si pretendiera reproducir la vida en movimiento al margen de esquemas muy estrictos. Aunque se vale de estereotipos, de soluciones posibles, da también algunas libertades a la imaginación; las gentes se apropian del mundo a través del arte, la literatura, la contemplación y no sólo de la ciencia. No fue un fracaso para las gentes del paleolítico, de la antigüedad o de cualquier época, en tanto pudieron organizar sus vidas, sus saberes y sus ambiciones, socialmente hablando. Para atrapar los hechos aplicaron otros logros previos y simultáneos: lenguajes, simbolismos, delimitación de ámbitos de significación, jerarquización, etc.

\section{LOS MITOS}

El mito implica una actitud ante la vida: afectividad hacia el entorno o simpatetismo; solidaridad fundamental; vinculación con todas las formas de vida (lo que pudo dar lugar, después, al totemismo o zoolatría); convicción sobre la unidad de la vida y, como rasgo general, culto a los antepasados ${ }^{18}$. LéviStrauss ${ }^{19}$ ha dicho que "las historias de carácter mitológico son, o lo parecen, arbitrarias, sin significado, absurdas" pero, como reaparecen en todas partes, evidentemente son propias del ser humano y resuelven algunas necesidades importantes para instalarse en el mundo. Y si, además de surgir en todas partes, han transpuesto diferentes etapas, tal importancia queda fuera de dudas, sólo resta saber cuáles aspectos problemáticos resolvieron y, aún hoy, probablemente resuelven. Al parecer, el mito proveyó unos medios de unidad y seguridad: con el entorno, con el grupo, con los dioses y con los ancestros. El ser, el estar y el permanecer fueron en alguna medida resueltos con el mito. "Ha sido a 
través de los mitos que el hombre ha resuelto las preocupaciones que iban más allá de la realidad tangible y causalmente inexplicable, de acuerdo con el estado de conocimientos y las estructuras del poder ${ }^{, 20}$.

Los mitos han resuelto las exigencias históricas de instalación en el mundo $\mathrm{y}$, aunque hayan cambiado los recursos y producciones culturales que continuaron cumpliendo esa función, los mitos no han desaparecido, sólo han adquirido nuevos contenidos porque más que tratarse de relatos fantásticos constituyen "una verdad psíquica, cultural, social que surge de la necesidad de equilibrio en las vivencias del mundo real y los impulsos de un sentimiento télico, trascendente y universalmente manifiesto ",21.

En la época moderna, el mito del progreso ha asumido la misma función en el contexto de la realidad y las expectativas actuales. Junto con la religión y la magia, el mito es un hecho social y como tal no es lícito que se le juzgue desde las perspectivas individuales e inmediatas, menos aún suponer que fracasó, o que no guarda relación alguna con el presente, o que su presencia en la historia de la humanidad corresponde a una etapa de incapacidad intelectual en la cual supuestamente la gente no percibía el "problema del tiempo". De acuerdo con Malinowski, me inclino a pensar que el mito cumplió una función muy importante al permitir a los seres humanos resolver exitosamente problemas de gran complejidad, acuciantes, en una época en que éstos aparecían muchas veces indiscernibles o más integrados. En el período lítico, las personas tuvieron delante un mundo que descubrir y en el cual pensar; también preguntas que hasta hoy nos asaltan, persistentes. Así aplicó su inteligencia, sus conoci- mientos y experiencias para inventar diversos artilugios capaces de satisfacer tales interrogantes o exigencias.

En el mito están contenidas respuestas de diversa índole como: fijar los hechos, tendencia permanente que expresa la voluntad de dominio, resistirse a la desaparición de fórmulas, inventos, soluciones ya puestas a prueba exitosamente; recordar, deseo vinculado a lo anterior, tener presente algo que ya pasó lo cual implica actualizar e integrar en tanto se ofrece a los demás lo ya logrado; diferenciarse o hacerse fuerte a través de la identidad; influir en los próximos y más lejanos, en los primeros para fortalecer los lazos de unidad y en los segundos para señalar los límites, marcar el territorio; explicarse los fenómenos, sus causas, su origen de manera comunitaria.

\section{LA HISTORIA}

La narración histórica refiere una secuencia de acontecimientos y cambios que idealmente no se quiebra en ninguna parte. Ha sido concebida como un relato en cadena de causas y efectos que sirven para explicar el presente. Además, se espera que la historia sea refrendada con hechos concretos que nos aseguren que así fue como ocurrió. En consecuencia, se trata de un relato que sigue unos cánones metodológicos y de nexo con la realidad perteneciente a una visión moderna de la actividad intelectual que refiere hechos ya ocurridos según las pautas que la Historia como disciplina ha establecido y practicado. Esta definición contemporánea no puede ser absolutizada en tanto los relatos de todo tipo son productos culturales y, por lo mismo, históricos. Quizá sería mejor que examinemos cómo se ha modificado el relato histórico a través del tiempo o cómo el ser 
humano ha resuelto en cada época su afán de registro, qué lo ha llevado a persistir en ese afán y qué clases de medios inventó para realizarlo según su tradición cultural.

En su versión moderna la historia es más especializada que en el pasado, pero tiene raíces comunes con el mito. En su génesis, atendió imperativos de la misma índole pero en su desarrollo ulterior tuvo que atender otros acoplándose a las exigencias de cada época. Su distanciamiento del mito ha ido ampliándose en virtud de su especialización y de las reglas que se impuso para ejercerla y perfeccionarla. Como el mito, la historia es un hecho social real, más allá de haberse instalado al interior de un tipo de relato o no, en tanto toda la producción cultural es histórica. Sólo una simplificación extrema puede llevarnos a creer que se trata de opuestos o de etapas evolutivas donde tiene que desaparecer uno para que la otra aparezca.

La historia, emergida del mito, pretendió ser comprensible y manejable ya no sólo para la comunidad sino que alcanzó mayor difusión entre distintos pueblos, conectando hechos verificables o reconocibles por otros, como recurso mnemotécnico consensual que fortaleció la identidad a la vez que establecía las diferencias. Probablemente al multiplicarse las interrelaciones que involucraban a sociedades distintas y ante la necesidad de reconocer orígenes comunes o ajenos, la historia resolvió en diferente medida las exigencias de legitimación y justificación.

Para Snell ${ }^{22}$ la poesía épica (Homero) cumplió un rol importantísimo en la fase de "desencantamiento" de los héroes y acontecimientos extraordinarios, permitiendo pasar al período de la saga: "La importancia que esta preocupación por la gloria tuvo en la formación de la conciencia histórica" es por eso muy importante. Las genealogías cumplieron el rol de asegurar la continuidad tanto como de recordar el carácter unitario de una comunidad. Entre los judíos la relación con el pasado es distinta a la de los griegos, a quienes les interesa ligar pasado con presente. Entre los antiguos pueblos del Perú, especialmente los Incas, las pacarinas u origen localizado de los pueblos no sólo favorecieron la identidad y el reconocimiento de linajes, sino que también fueron un medio legitimador de derechos sobre un territorio y sus recursos.

\section{COMPONENTES IDEOLÓGICOS MODERNOS}

Los componentes ideológicos contemporáneos tienen sus correspondientes expresiones históricas desde tiempos remotos, especie de construcciones ideológicas muy móviles, en formación, con una complejidad extendida (o extensa) que, con el correr de la historia, van a ramificarse en conceptualizaciones más precisas. Algunas de ellas, de antigua data, son: el valor de la razón, la importancia de la crítica, el interés y el ejercicio de registrar hechos de importancia personal, familiar y comunitario (afán histórico), la vocación por el orden, la idea de avance perpetuo (progreso, evolución), antropocentrismo, etnocentrismo y recenscentrismo. Hay abundantes datos que dan cuenta de esta formación histórica del pensamiento actual.

Complementariamente, el contenido de estas unidades ideológicas significantes están conectados, se afianzan mutuamente y han tendido a pasar de una complejidad extensa a una complejidad intensa, entendiéndose por la primera a toda construcción ideológica 
orientada a resolver varios cometidos, mayormente implícitos e inconscientes, y por la segunda a aquellas otras que se desprenden de las primeras por procesos de especialización y que, por lo tanto, tienden a resolver objetivos más precisos. Este desenvolvimiento provee de nuevos conceptos y términos, lo que contribuye a afianzar la idea de separación, de corte total entre épocas y a perder de vista el carácter mismo de los cambios en el pensamiento, más aún si la vigencia de la ideología evolucionista se impone a nuestra capacidad de análisis. Esto último es clave porque lleva la posibilidad o imposibilidad de aproximarnos a una mejor comprensión de la naturaleza humana.

Las concepciones de avance, de evolución y progreso son antiguas pero se afianzaron con la modernidad, a partir de la Ilustración, más aún con la revolución industrial. A partir de ellas se configuran diferentes corrientes y escuelas de pensamiento como el ya mencionado evolucionismo, el socialismo utópico, el marxismo o socialismo científico, la propuesta de Comte que asigna al positivismo un rol culminante, etc. $y$, en términos más generalizados, la aceptación masiva del progreso como un hecho indubitable. Se trata de una especie de cosmovisión predominante, quizá en riesgo actual de entrar en crisis por la problemática medioambiental de proporciones globalizadas.

Una de las áreas problemáticas es la relación de las ideas de avance indetenible con la historia, la conciencia histórica y la filosofía de la historia. Otra muy importante es la relación de dichos conceptos con la modernidad, las críticas a la modernidad y con la posmodernidad. Asimismo, habría que descubrir las conexiones teóricas y prácticas, que el tópico de progreso ha introducido en las relaciones económicas y de poder a nivel global e internacional. En el plano hermenéutico e ideológico, se debe intentar un acercamiento a los significados más profundos ligados a la vida y a la historia.

\section{NOTAS}

(1) Weber, A. 1960 (1935): 18. No coincidimos con Weber, sin embargo, cuando su interpretación histórica excluye a América, África, Australia e Islas del Pacífico de los procesos culturales primigenios importantes (Ibid.13) para la humanidad, lo que se explica por el estado del conocimiento en las primeras décadas del siglo XX. Es verdad que América es el continente más joven, pero los que la habitaron (gente del Paleolítico superior) trajeron la cultura de la piedra, sobre cuya base se constituye después la Gran Área Cultural Andina, como la llamó Carl Troll, $\mathrm{y}$ otras en Mesoamérica (Aztecas y Mayas). En América se descubren las posibilidades agrícolas, se crean ciudades y estados.

(2) Su presencia ha sido calculada desde hace aproximadamente 150,000 años, para extinguirse 120,000 años después. Algunas fuentes dicen, sin embargo, que desapareció hace 50,000 años y otras que hace 25,000 .

(3) No necesariamente por herencia cultural lejana, sino por ser parte de la naturaleza humana.

(4) Tan bien explicados por F.Bacon (1984 (1620): Libro Primero, 39-53 pp (38-62) en su Novum organum: "Los ídolos y las nociones falsas que han invadido ya la humana inteligencia, de 
tal suerte, que la verdad sólo puede encontrar a ella difícil acceso; y no sólo esto sino que, obtenido el acceso, esas falsas nociones, concurrirán a la restauración de las ciencias, y suscitarán ... obstáculos mil, a menos que prevenidos los hombres, se pongan en guardia contra ellos, en los límites de lo posible" (39-40 pp.)

(5) Para Weber, cada tipo de ser humano incorpora rasgos y capacidades cualitativamente diferentes de su predecesor.

(6) Weber, A. op.cit. 18-22

(7) Ferrater Mora, 1999: IV: 3756

(8) Abbagnano y Fornero, 2004: 194

(9) $1987: 26-27$

(10) $1945: 254-255$

(11) Ibid. 255

(12) 1965:215-230)

(13) Habermas, 2002: 22

(14) Ibid. 2008: 15-16

(15) Apud. Habermas, Loc. cit.

(16) $1987: 2,37$

(17) Ibid. I: 28. Aquí "en esencia" sólo significa "cumpliendo una misma vocación connatural al ser humano".

(18) Cassirer, op. cit. 130

(19) $1987: 30$.

(20) Silva Santisteban, 2004: 143

(21) Loc. cit.

(22) $1965: 217-219$

\section{BIBLIOGRAFÍA}

ABBAGNANO, Nicola y FORNERO, Giovanni. (2004). Diccionario de Filosofía. México D.F. Fondo de Cultura Económica (FCE).
BACON, Francis. (1984) (1620): Novum organum. Madrid, SARPE, tomo 47.

CASSIRER, Ernst. (1945). Antropología filosófica. México D.F. Fondo de Cultura Económica (FCE).

FERRATER MORA, José. (1999). Diccionario de filosofía. En 4 volúmenes. Barcelona, Editorial ARIEL.

HABERMAS, Jürgen. (2002). La modernidad, un proyecto incompleto. En Varios: La posmodernidad. Barcelona, Editorial KAIROS.

(2008). El discurso filosófico de la modernidad. Buenos Aires, KATZ editores.

LÉVI-STRAUSS, Claude. (1987). Mito y significado. Madrid, Alianza Editorial.

MALINOWSKI, Bronislaw. (1984). Una teoría científica de la cultura. Madrid, Editorial SARPE.

SILVA SANTISTEBAN, Fernando. (2005). El primate responsable. Lima, Fondo Editorial del Congreso de la República.

SNELL, Bruno. (1965). Las fuentes del pensamiento europeo. Madrid, Editorial Razón y Fe, S.A.

WEBER, Alfred. (1960). Historia de la cultura. México, Fondo de Cultura Económica (FCE) 